\title{
Evidence for a Role of the Shell of the Nucleus Accumbens in Oral Behavior of Freely Moving Rats
}

\author{
Eric P. M. Prinssen, Walter Balestra, Frank F. J. Bemelmans, and Alexander R. Cools \\ Department of Psycho- and Neuropharmacology, University of Nijmegen, Nijmegen, The Netherlands
}

\begin{abstract}
Behavioral effects of intra-accumbens administration of the dopamine $\mathrm{DA}_{i}$ receptor agonist (3,4-dihydroxyphenylimino)2-imidazoline (DPI) were studied in freely moving rats. Three distinct areas were examined: core, shell and "shore," namely, the border region of the core and shell. DPI $(5 \mu \mathrm{g})$ administered into the shell, but not areas ventral to the shell, increased chewing, tongue protrusion, sniffing, and grooming; it also induced abnormal oral behavior, namely, largeamplitude chewing. A similar dose of DPI administered into the core did not affect any (peri-)oral behavior, except sniffing. Because of methodological constraints the receptor specificity of the DPI effects was studied in rats with cannulas directed at the shore. DPI $(5.0-10.0 \mu \mathrm{g})$ administered into the shore increased oral behavior dose dependently; however, the dose-effect curve varied per distinct type of oral behavior. The dopamine $\mathrm{DA}_{\mathrm{i}}$ receptor antagonist ergometrine attenuated the effect of DPI on tremor, chewing, and sniffing frequencies. Taken together, the data show that the effects of DPI were $D A_{i}$ receptor specific. It is concluded that stimulation of dopamine $\mathrm{DA}_{\mathrm{i}}$ receptors in the shell modulates and induces (peri-)oral behaviors in freely moving rats.

[Key words: orofacial dyskinesia, dopamine $D A_{\text {, receptors, }}$ DPI [(3,4-dihydroxyphenylimino)-2-imidazoline], ergometrine, nucleus accumbens, shell, core, rat]
\end{abstract}

The idea that the nucleus accumbens is a homogeneous structure is disappearing. During the last 10 years differences have been found between core and shell with respect to anatomy (Zaborsky et al., 1985; Voorn et al., 1989; Heimer et al., 1991; Rerendse et al., 1992; Zahm and Brog, 1992; and others), receptor density (Bardo and Hammer, 1991), pharmacology (Deutch and Cameron, 1992), and electrophysiology (Pennartz et al., 1992). Still, with respect to behavior of freely moving rats, no studies on differences between core and shell have been performed. Therefore, the aim of this study was to analyze the role of different parts of the nucleus accumbens in modulating behavior.

The nucleus accumbens modulates oral behavior in rats (Bordi et al., 1989; Cools, 1990; Koshikawa et al., 1990, 1991; Prinssen et al., 1992; Koene et al., 1993). It has been found that intra-accumbens administration of the dopamine $\mathrm{DA}_{i}$ receptor

\footnotetext{
Received Mar. 11, 1993; revised July 1, 1993; accepted Aug. 26, 1993
}

We express our gratitude to Dick Heeren for his valuable support with programming, and to Luuk Lubbers for the learning of operation techniques. Boehringer Ingelheim generously supplied DPI. This study was supported by the Dutch Society for Scientific Research (NWO) 900-548-119.

Correspondence should be addressed to Prof. Dr. A. R. Cools, Department of Psycho- and Neuropharmacology, University of Nijmegen, P.O. Box 9101, 6500 HB Nijmegen, I he Netherlands.

Copyright (C) 1994 Society for Neuroscience $0270-6474 / 94 / 141555-08 \$ 05.00 / 0$ agonist (3,4-dihydroxyphenylimino)-2-imidazoline (DPI) increases oral behavior in rats (Cools, 1990). In cats, the same drug (DPI) has been found to induce abnormal oral movements, namely, orofacial dyskinesias (OFD), when administered into a well-delineated striatal subarea (Cools et al., 1976; Spooren et al., 1991). Accordingly, DPI was considered to be a valid tool to study the putative, differential involvement of the core and shell of the nucleus accumbens in oral behavior of freely moving rats. In the present investigation the behavioral effects of DPI injections into the core were compared with those elicited by DPI injections into the shell. The outcome of this study shows that administration of DPI $(5 \mu \mathrm{g})$ into the shell, but not the core, increased and induced oral behaviors. However, since it was difficult to hit the shell correctly, the "shore," namely, the border region of the core and shell, was chosen as the target area for studying the specificity of the DPI-induced effects. First, a doseeffect curve was made. Second, DPI was combined with the dopamine $\mathrm{DA}_{\mathrm{i}}$ antagonist ergometrine (Struyker Boudier et al., 1975; Cools et al., 1976).

\section{Materials and Methods}

Subjects. Naive, male Wistar rats $(n=7-16$ animals per group; Central Animal Laboratory, Nijmegen, The Netherlands) were used. Before operation they weighed between 180 and $220 \mathrm{gm}$. Rats were individually housed and kept on a 12:12 hr light/dark cycle with lights on at 07:00. Food and water were available ad libitum. Animals were used only once.

Surgery. Animals were anesthetized with sodium pentobarbital (Narcovet, $60 \mathrm{mg} / \mathrm{kg}$. i.p.). Guide cannulas ( $0.65 \mathrm{~mm}$ o.d., $0.3 \mathrm{i} . \mathrm{d}$.), were stereotactically implanted into the core (anterior, $10.0 \mathrm{~mm}$; lateral, 1.3 $\mathrm{mm}$ ), the shell (anterior, $9.8 \mathrm{~mm}$; lateral, $0.5 \mathrm{~mm}$ ), or the border region of the core and shell (the "shore"; anterior, $9.8 \mathrm{~mm}$; lateral, $1.2 \mathrm{~mm}$ ). Cannulas ( $5 \mathrm{~mm}$ length) directed at the core and shore were angled $10^{\circ}$, and cannulas $\left(6 \mathrm{~mm}\right.$ length) directed at the shell were angled $15^{\circ}$ from the midsagittal plane to avoid the ventricular system and to leave space for an EMG connector. Cannulas were fixed onto the skull with dental cement (Durelon, ESPE; carboxylate cement) aided by the attachment of two screws. Electrodes were placed in the masseter and digastric muscles (for details, see Prinssen et al., 1992). The five-pole EMG connector was attached to the skull with dental cement.

Apparatus. Observations were done in a cage of Plexiglas $(25 \mathrm{~cm} \times$ $25 \mathrm{~cm} \times 35 \mathrm{~cm}$ ). A mirror (angled $45^{\circ}$ ) was mounted beneath the cage allowing the precise recording of behavior, especially of oral movements. Behavior was registered using a protocol panel with 16 channels. The behavioral protocols (and the EMG signals) were directly read into a computer and analyzed by a computer program that calculated the frequency and duration of every scored behavior. Since a reliable method allowing the calculation of the correlation of the EMG data and the behavioral data was not yet available, it was decided to present the EMG data that require a completely different analysis in a separate report.

Procedure. After surgery the rats were housed individually in the original stockroom and allowed recovery from operation for at least 1 week. After the recovery period, rats were handled on 3 subsequent 




$=$ intra-cerebral injection

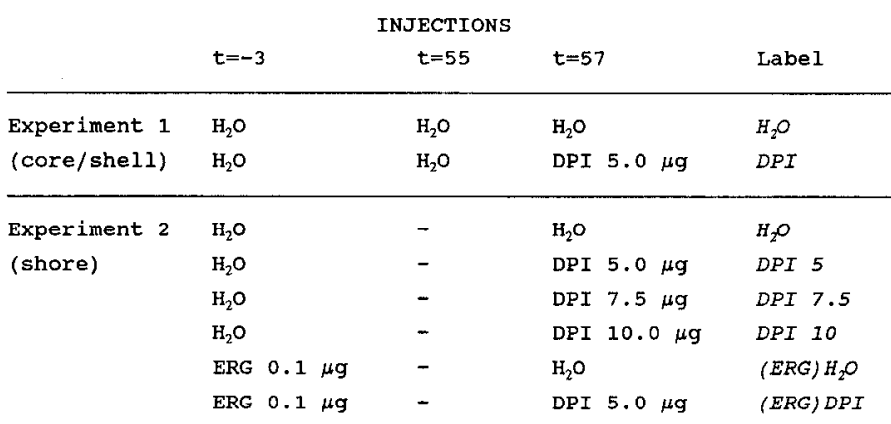

Figure 1. The experimental paradigm. An experiment lasted from $t=$ $-10 \mathrm{~min}$ to $t=90 \mathrm{~min}$ per rat. The names of the different groups are shown in the Label column. -, no injection was given; $E R G$, ergometrine.

days and tested on the fourth day. The handling and test procedures included a habituation time of $45 \mathrm{~min}$. The rats were handled for $5 \mathrm{~min}$ on day 1 . On day 2 the rats were handled for $5 \mathrm{~min}$ and the inner cannulas were taken out and put back again. On the third day the rats were handled for $5 \mathrm{~min}$, a sham injection was given, and the rats were connected to the EMG and placed in the experimental box for $10 \mathrm{~min}$. On the test day the following paradigm was assessed (see Fig. 1). The rats were placed at $t=-10 \mathrm{~min}$ in the observation box and connected with the EMG device, which itself did not affect the behavioral freedom of the animals (Koene et al., 1993). Subsequently, intracerebral injections were bilaterally given at $t=-3 \mathrm{~min}$. Recording of baseline activity started at $t=0 \mathrm{~min}$ and lasted $30 \mathrm{~min}$ (pretreatment session), after which the rats were placed in the resting cage. The rats were placed in a new observation box at $t=50 \mathrm{~min}$. Finally, the animals received their last intracerebral injection at $t=57 \mathrm{~min}$. Recording of the drug effects started at $t=60 \mathrm{~min}$ and lasted $30 \mathrm{~min}$ (experimental session). During the habituation, pretreatment, and experimental sessions, the environmental conditions were kept constant. DPI and its corresponding control $\left(\mathrm{H}_{2} \mathrm{O}\right)$ were always given at $t=57$, whereas ergometrine and its corresponding control $\left(\mathrm{H}_{2} \mathrm{O}\right)$ were given at $t=-3$, namely, 60 min before the experimental session. In previous experiments (Cools, 1978), it has been found that ergometrine given $60 \mathrm{~min}$ prior to DPI has its strongest antagonistic action. In order to include a control for future studies on the efficacy of putative dopamine $\mathrm{DA}_{\mathrm{i}}$ receptor antagonists that act immediately after administration, rats tested in experiment 1 (Fig. 1) received an additional injection of distilled water at $t=55$ min (Fig. 1). Apart from the fact that distilled water injections into the nucleus accumbens are known to be adequate controls (Pijnenburg et al., 1976), such additional injections do not produce any tissue damage as long as the number of injections is limited to six (Cools, 1986). Injections were given by means of a $5 \mu$ l syringe with a $0.25 \mathrm{~mm}$ needle that extended into the brain tissue below the tip of the permanently embedded cannula (1.6 $\mathrm{mm}$ for core; $2.0 \mathrm{~mm}$ for shore; shell injection depth was individually calculated by stereotactic measures, normally about $1.7 \mathrm{~mm}$ ). The volume was $0.5 \mu$ injected over a $10 \mathrm{sec}$ period, and the needle was left in situ for another $10 \mathrm{sec}$ to minimize diffusion along the needle tract. After the experiment rats were killed, and brains were dissected. Brain sections were stained with cresyl violet and microscopically analyzed. In principle, only data from subjects with injections made into the desired sites were further analyzed on the condition that no histological damage around the injection site was found.

About $50 \%$ of the injections directed at the shell were misplaced. For that reason, these groups were supplemented until the required number of animals per group $(N=7-9)$ was reached. Habituation and testing occurred between 9:00 and 17:00.

Behavioral observations. The following ethogram of behavioral elements was used to record behavior: (1) chew (movement of the lower jaw vertical and/or lateral in a single or repetitive fashion without an object between the teeth), (2) gnaw [movement of the lower jaw vertical and/or lateral in a single or repetitive fashion with an object (pieces of straw, feces, or the box wall) between the teeth], (3) tremor (rapid oscillations of cheek and/or lower jaw), (4) tongue protrusion (not aimed at an object), (5) lick (tongue protrusion aimed at an object), (6) yawn (wide opening of the lower jaw with bare teeth), (7) sniff (exploratory behavior with moving vibrissae close to an object), and (8) groom (face washing, licking the fur, and scratching). Continuous succession of identical elements of behavior (bouts) were scored as a single event; this held true for all behaviors except tongue protrusion and yawn. Duration (except for tongue protrusion and yawn) and frequency of all behaviors were analyzed.

Drugs. DPI (Boehringer lngelheim, Germany) and ergometrine maleate (Sigma, St. Louis, MO) were dissolved in distilled water. The $\mathrm{pH}$ (5-6) and osmolality of the resulting solutions are known to remain devoid of any behavioral effect (Pijnenburg et al., 1976). The dose of ergometrine was limited to $0.1 \mu \mathrm{g}$, since higher doses are known to produce locomotor activity (Cools, 1986). The drug solutions were prepared less than $15 \mathrm{~min}$ prior to the injection. Drugs were injected bilaterally.

Statistical analysis. Given the large individual variation in oral behaviors, it was decided to calculate the drug-induced changes per rat as follows. The scores collected per rat during the pretreatment session were subtracted from the scores collected per rat during the experimental session. Only the resulting data were statistically analyzed. The effects of DPI in the core and shell groups $\left(\mathrm{H}_{2} \mathrm{O}\right.$ group vs DPI group) were analyzed with two-tailed $t$ tests $(P$ values $<0.05$ considered to be significant; experiment 1). The effects of different doses of DPI (experiment 2 ) were analyzed with a one-way ANOVA with four levels $\left(\mathrm{H}_{2} \mathrm{O}\right.$, DPI 5, DPI 7.5, and DPI 10 groups). In case of a $P$ value $<0.05$, a post hoc multiple comparison test (Student-Newman-Keuls) was performed. The data concerning the experiment in which the ability of ergometrine $(0.1$ $\mu \mathrm{g})$ to antagonize the DPI-induced $(5.0 \mu \mathrm{g})$ effects were investigated, were analyzed with a two-tailed $t$ test [(ERG)DPI vs DPI 5 group). The same test was used to determine possible effects of ergometrine alone [(ERG) $\mathrm{H}_{2} \mathrm{O}$ vs $\mathrm{H}_{2} \mathrm{O}$ group], a necessary control.

\section{Results}

\section{Histology}

The injection sites of the animals in the core and shell were only accepted as properly placed, when both injection places fell entirely in the desired areas according to the atlas of Paxinos and Watson (1986). A representative series of these sites is shown in Figure 2. Four animals were discarded because of histological damage found around the injection site. Subjects with misplaced injections were also discarded apart from those with bilateral injections in areas that were adjacent and ventral to the shell, namely, the islands of Calleja and the olfactory tubercle (see below).

\section{Data representation}

As mentioned in the Materials and Methods, the scores collected during the pretreatment session showed a large individual variation. Accordingly, it was decided to correct the scores collected during the experimental session for those collected during the pretreatment session by a subtraction procedure per rat. The resulting data are shown in Figures 4-7. To illustrate the individual variation in the raw data, the scores of the behavior that showed the strongest effect, namely, the DPI-induced increase in chewing frequency following its administration into the shell or shore (see below), are given in Figure 3. This figure presents the raw scores of the pretreatment and experimental sessions of four series of experiments: shell, $\mathrm{H}_{2} \mathrm{O}$ (pretreatment session) $5 \mu \mathrm{g}$ DPI (experimental session) and its corresponding control 

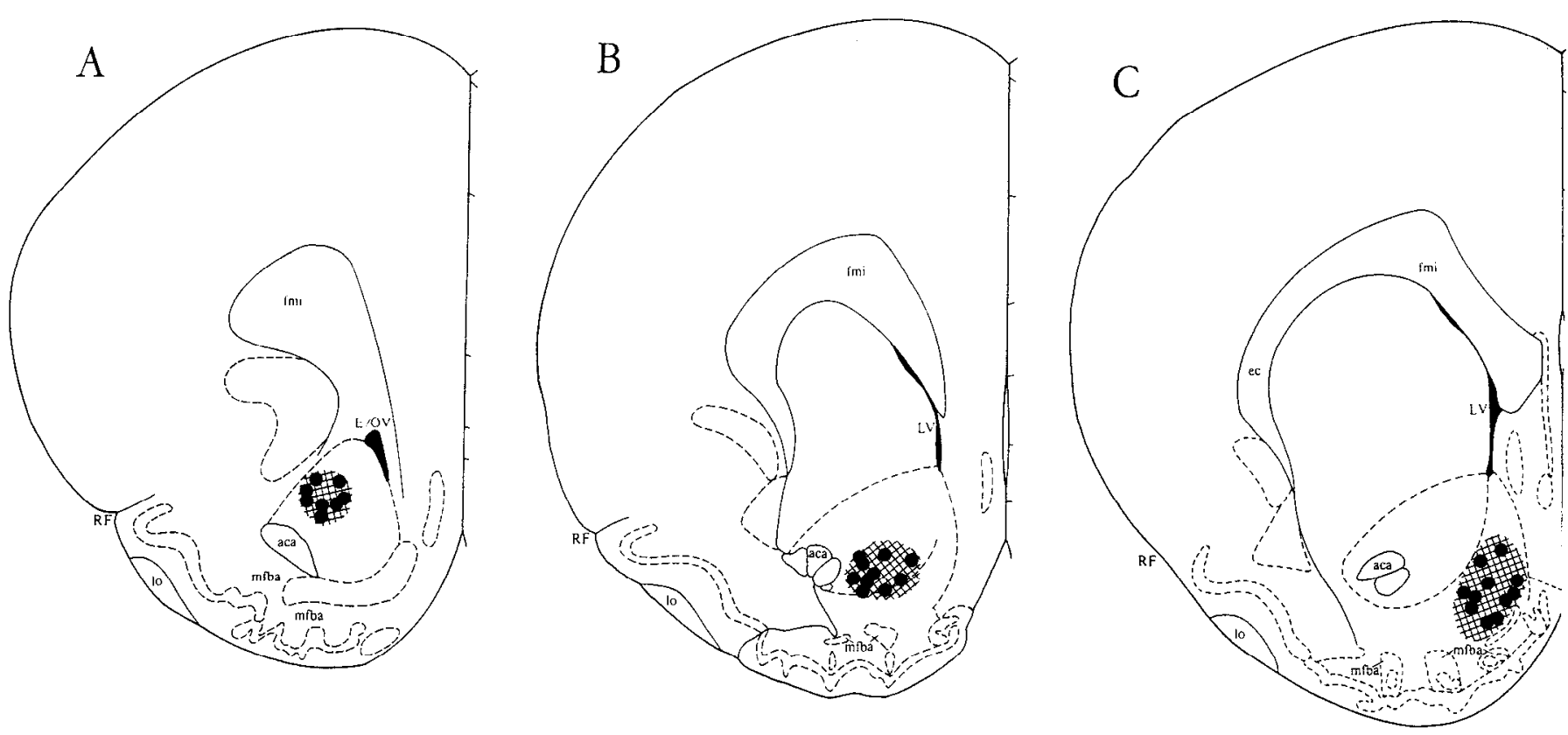

Figure 2. The areas in which the injection places were located for the core $(A)$, the shore $(B)$, and the shell $(C)$ according to the atlas of Paxinos and Watson (1986). Representative injection sites are shown.

$\mathrm{H}_{2} \mathrm{O}-\mathrm{H}_{2} \mathrm{O}$; shore, $\mathrm{H}_{2} \mathrm{O}$ (pretreatment session) $-7.5 \mu \mathrm{g}$ DPI (experimental session) and its corresponding control $\mathrm{H}_{2} \mathrm{O}-$ $\mathrm{H}_{2} \mathrm{O}$. The scores collected in the experimental sessions were evidently coupled to the scores collected during the pretreatment session: in both cases a significant correlation was found between pretreatment and experimental scores (the lumped DPI groups: Pearson correlation coefficient, $R=0.66, P<0.01$; the lumped $\mathrm{H}_{2} \mathrm{O}$ groups: Pearson correlation coefficient, $R=0.65, P<0.01$ ). Moreover, a linear regression equation was sufficient to represent adequately the relation of pretreatment and experimental sessions in both cases (DPI data: linear regression, $R^{2}=0.42$, $F$ ratio $=10.2, P<0.01 ; \mathrm{H}_{2} \mathrm{O}$ data: linear regression, $R^{2}=0.44$, $F$ ratio $=10.9, P<0.01$ ). These data together with the finding that the lines through each of the data sets have exactly the same coefficient $(0.68)$ provided a firm foundation for the reliability of the subtraction procedure assessed to evaluate the data.

\section{Effects of DPI in the core and shell}

Normal oral behavior. Figure 4 shows the effect of DPI $(5 \mu \mathrm{g})$ in the core and shell on (peri-)oral behaviors. Since the scores in the pretreatment session were subtracted from those in the expcrimental scssion, some of these parameters were negative (Fig. 4): in the control groups $\left(\mathrm{H}_{2} \mathrm{O}\right.$ groups), oral behaviors occurred less during the experimental session than during the pretreatment session. With respect to the effects of DPI, Figure 4 shows clearly that $5 \mu \mathrm{g}$ of DPI was highly effective when administered into the shell, and nearly ineffective when administered into the core.

DPI administered into the shell significantly increased the frequency of chewing $(P=0.03)$, tongue protrusion $(P=0.03)$, sniffing $(P=0.04)$, and grooming $(P=0.04)$. DPI administered into the shell increased the duration of chewing $(P=0.001)$ and sniffing $(P=0.03)$, but not of grooming $(P=0.38)$. DPI administered into the shell affected neither the frequency nor the duration of gnawing, tremor, yawning, or licking $(P>0.1$ for every variable). Since the increase in the chewing frequency was the most prominent feature of DPI injections in the shell, this variable was also analyzed in subjects with injections in areas that were adjacent and ventral to the shell $(N=7)$. The effect of DPI in the latter animals was much smaller than that found in animals with injections placed in the shell [means \pm SEM,

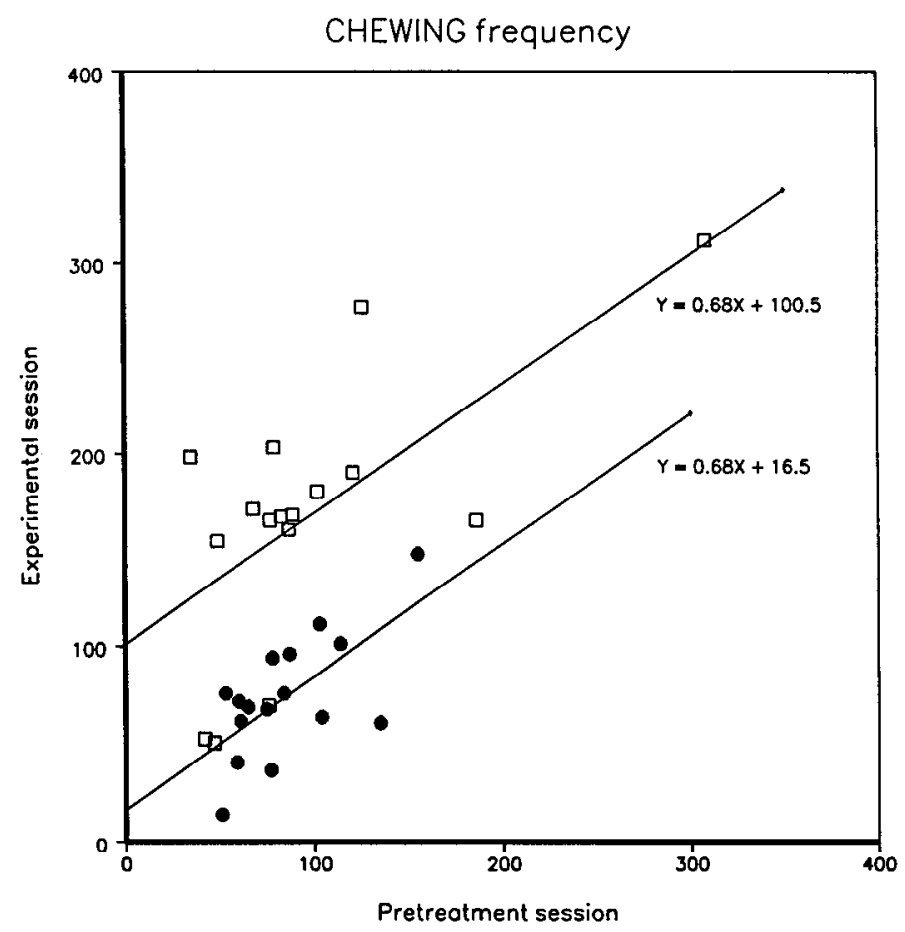

Figure 3. The pretreatment values (x-axis) and experimental values $(y$-axis) from two DPI groups [the group that received DPI $(7.5 \mu \mathrm{g})$ in the shore and the group that received DPI $(5 \mu \mathrm{g})$ in the shell; open squares] and from the two respective control groups (the control group of the shore and the control group of the shell; solid circles) are shown with respect to chewing frequency. Correlations between pretreatment and experimental scores were significant (see Results). 
CHEW

frequency



TREMOR

frequency

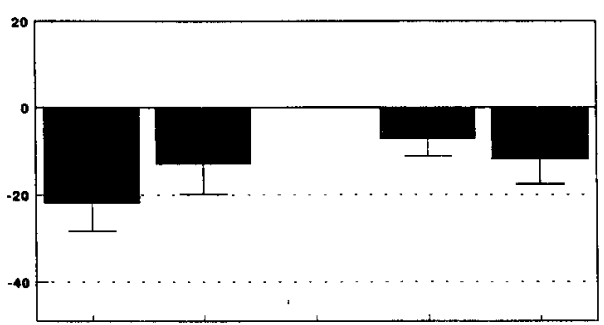

SNIFF

frequency

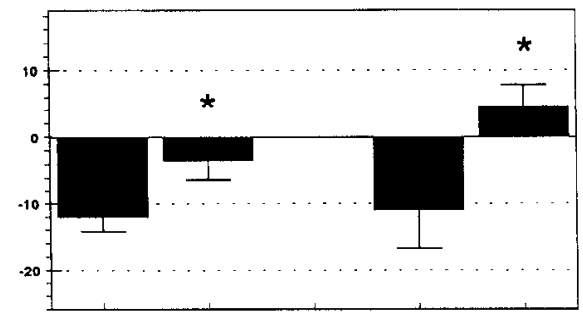

GROOM

frequency

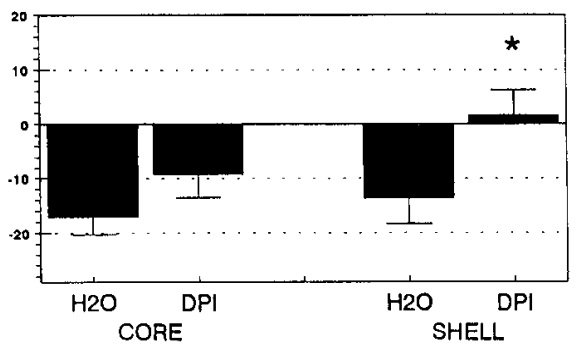

GNAW

frequency

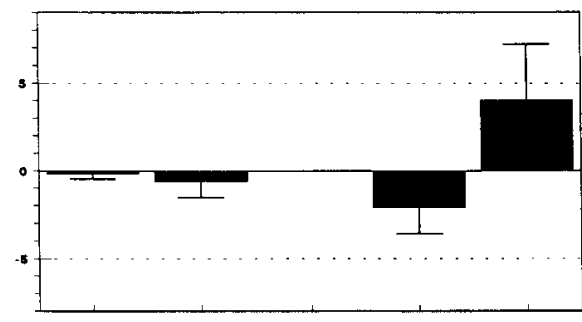

TONGUE PROTRUSION frequency

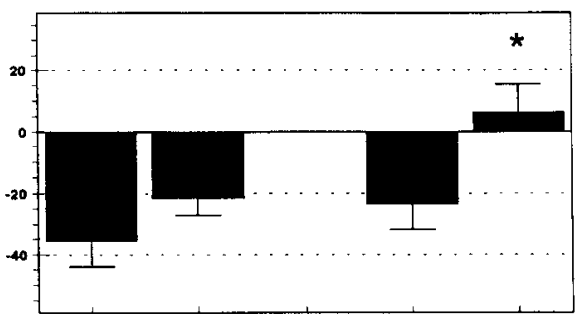

SNIFF duration



GROOM

duration

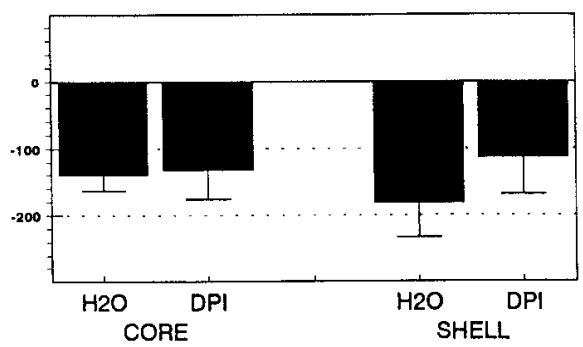

Figure 4. The effects of DPI $(5 \mu \mathrm{g})$ in the core and shell on (peri-)oral behaviors. Except for tongue protrusions, the frequencies of bouts of behavior are shown. Durations are given in seconds. Means and SEM are given. ${ }^{*}, P<0.05$ compared with the $\mathrm{H}_{2} \mathrm{O}$ group.
$0.04)$ and duration $(P=0.01)$. This behavior was never observed in untreated rats.

\section{Effects of DPI and ergometrine in the shore}

Normal oral behavior. Figure 6 shows the effects of administration of different doses of DPI into the shore on (peri-)oral behaviors. One-way ANOVA values were significant for the frequency of chewing $[F(3,29)=7.93, P<0.001]$, gnawing $[F(3,29)$ $=5.63, P=0.004]$, tremor $[F(3,29)=8.40, P<0.001]$, and sniffing $[F(3,29)=5.68, P=0.004]$. With respect to chewing frequency, a bell-shaped curve, with all groups significantly greater than controls, was found (Fig. 6). The DPI 7.5 group ministration of DPI (and, rarely, $\mathrm{H}_{2} \mathrm{O}$ ) into the shell, but not the core, increased the large-amplitude chewing frequency $(P=$ 


\section{LARGE AMPLITUDE CHEW frequency}

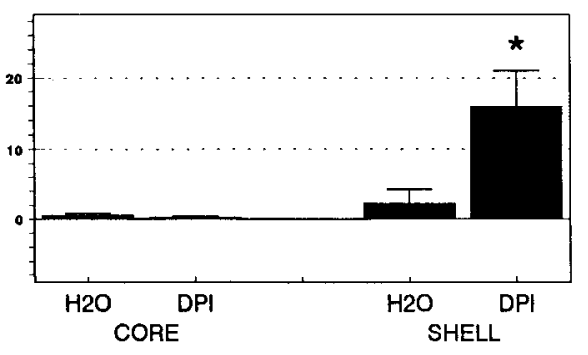

\section{LARGE AMPLITUDE CHEW duration}

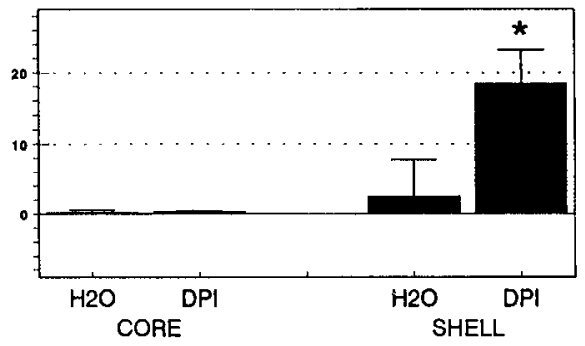

Figure 5. The effects of DPI $(5 \mu \mathrm{g})$ in the core and shell on large-amplitude chewing. The frequency of bouts of large-amplitude chewing is shown. Duration is given in seconds. Means and SEM are given. ${ }^{*}, P<0.05$ compared with the $\mathrm{H}_{2} \mathrm{O}$ group. showed the highest peak, which was significantly higher than the DPI 5 group $(P<0.05)$. With respect to gnawing frequency, a dose-dependent increase was observed (with DPI 7.5 and DPI 10 groups significantly greater than controls). The increase in tremor frequency showed a bell-shaped curve with significant increases in the DPI 5 and DPI 7.5 groups, which disappeared at the highest dose tested. A similar increase was seen with tongue protrusion frequency; however, none of the values reached significance. All DPI groups significantly increased sniffing frequency, but not in a dose-dependent manner. DPI did not affect the frequency of tongue protrusions, yawning, licking, or grooming compared with controls (one-way ANOVA, $P>0.1$ for all variables).

One-way ANOVA values were significant for the duration of chewing $[F(3,29)=7.17, P=0.001]$, gnawing $[F(3,29)=5.20$, $P=0.005]$, and tremor $[F(3,29)=7.98, P<0.001]$. Chewing, gnawing, and tremor duration showed dose-effect curves that were similar to those of the frequencies of these behaviors. DPI did not affect the duration of licking, sniffing, or grooming compared with controls ( $P>0.1$ for all variables). Although ergometrine was administered before the pretreatment session (Fig. 1), it did not affect any behavior during the pretreatment session (data not shown), nor was behavior during the experimental session affected by ergometrine when given alone [ $(E R G) \mathrm{H}_{2} \mathrm{O}$ vs $\mathrm{H}_{2} \mathrm{O}$; Fig. 6]. Ergometrine significantly decreased the DPIinduced increase in tremor frequency $(P=0.04)$, chewing frequency $(P=0.01)$, and sniffing frequency $(P=0.03)$. Ergometrine nonsignificantly decreased the DPI-induced increase in tremor duration $(P=0.07)$ and chewing duration $(P=0.09)$. Since the DPI 5 group did not significantly increase gnawing, the effect of ergometrine could not be assessed in this case.

Abnormal oral behavior. With respect to large-amplitude chewing, the analysis of the cffcct of DPI administration into the shore was limited to the percentage of animals showing this behavior during chewing in the experimental period (Fig. 7). Large-amplitude chewing occurred significantly more often in the DPI 7.5 and DPI 10 groups than in the control group (Fischer's exact probability test, $P<0.001$ for each group) and the DPI 5 group (Fischer's exact probability test, $P=0.05$ for each group). Because $5.0 \mu \mathrm{g}$ orDPI did not significantly increase largeamplitude chewing, the effect of ergometrine could not be assessed.

\section{Discussion}

General

The present study analyzed changes in (peri-)oral behavior that occurred after administration of DPI or $\mathrm{H}_{2} \mathrm{O}$ in different areas of the nucleus accumbens in freely moving rats. As discussed below, DPI enhanced and elicited oral behaviors following its administration into the shell and shore, but not the core, of the nucleus accumbens. Given the large individual variability in individual scores collected during the pretreatment sessions, it was decided to subtract per rat the scores collected during the pretreatment session from those collected during the experimental session. Figure 3 shows that this method adequately accounted for the individual differences found. Apart from the finding that the scores of the experimental sessions significantly correlated with those of the pretreatment sessions, it was found that the coefficient of the lines fitting the data set of the DPI experiments and the one fitting that of the control experiments were identical. These data also prove that the DPI-induced changes were not due to only a subpopulation of animals.

Figures 4-7 show that distilled water given before the experimental session reduced the vast majority of oral behaviors, when compared with the scores collected during the pretreatment sessions. Given the fact that the animals were not habituated to the injection given before the pretreatment sessions, it is not unlikely that the first injection elicited and/or enhanced oral behaviors as a stress response to the injection. Indeed, the nucleus accumbens, especially the shell region, is known to be very sensitive to stressors (Deutch and Cameron, 1992). Taking this consideration into account, it can be speculated that the observed decrease was due to the weaning of this effect. From this point of view it might even be speculated that the DPIinduced increases in oral behaviors, which will be discussed below in more detail, were due to changes in susceptibility to stress. Although this possibility cannot be excluded, it does not explain why DPI elicited abnormal oral behavior, namely, a behavior that was never seen in untreated rats. In fact, the latter data indicate that DPI did not simply reinstate the original situation. The recently reportcd finding that administration of DPI into the shell produces jaw movements in anesthetized and spinalized rats (Cools et al., 1993) also indicates that the DPIinduced display of oral behavior is rather independent of stress. In sum, the mechanism underlying the DPI effects remains to be investigated.

\section{DPI-induced effects}

The present study confirms and extends the earlier finding that DPI administration into the nucleus accumbens increases oral behavior in freely moving rats (Cools, 1990). Administration of the dopamine $\mathrm{DA}_{\mathrm{i}}$ receptor agonist DPI $(5 \mu \mathrm{g})$ into the shell of the nucleus accumbens increased chewing, tongue protrusion, sniffing, and grooming, and induced abnormal oral movements, namely, large-amplitude chewing. Since injections made outside, but adjacent to, the shell showed much smaller effects, the 
CHEW

frequency



TREMOR

frequency

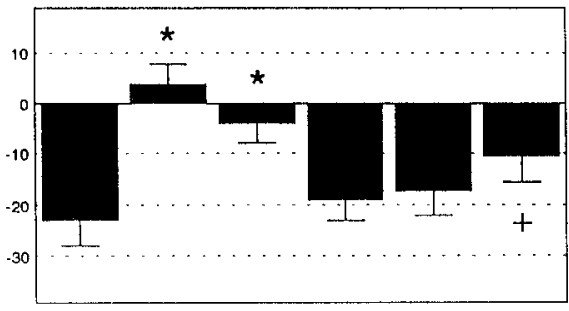

SNIFF

frequency

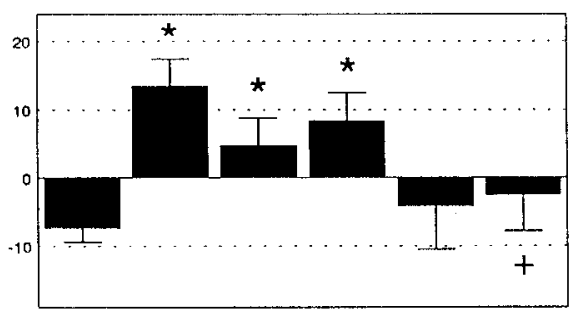

GROOM

frequency

Figure 6. The effects of various dose of DPI in the shore on (peri-)oral behaviors. In addition, the effects of 0.1 $\mu \mathrm{g}$ of ergometrine $(E R G)$, given $60 \mathrm{~min}$ prior to $5.0 \mu \mathrm{g}$ of DPI or $\mathrm{H}_{2} \mathrm{O}$, are shown. Except for tongue protrusions, the frequency of bouts of behavior is shown. Durations are given in seconds. Means and SEM are given. ${ }^{*}, P<0.05$ compared with the $\mathrm{H}_{2} \mathrm{O}$ group;,$+ P<0.05$ compared with the DPI 5 group.
GNAW

frequency



TONGUE PROTRUSION frequency

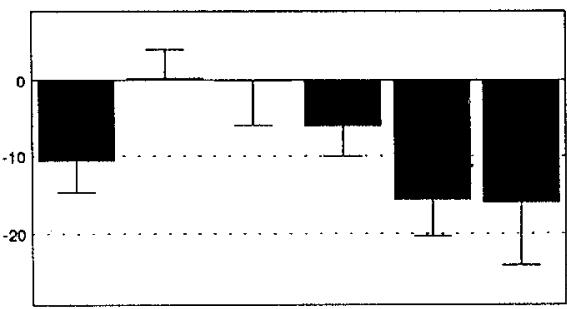

SNIFF duration

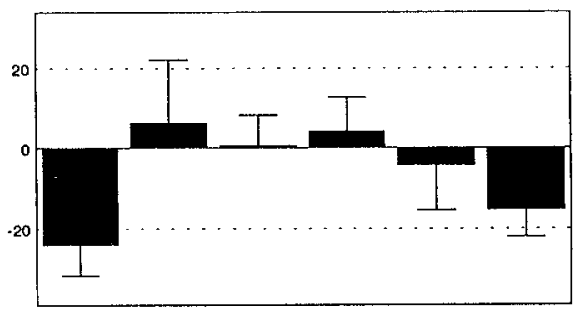

GROOM duration
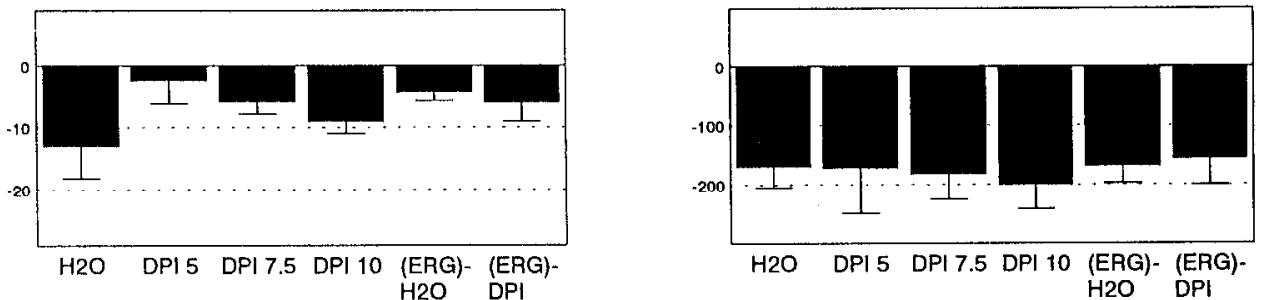

effects of DPI in the shell are considered to be region specific. Administration of $5 \mu \mathrm{g}$ of DPI in the core of the nucleus accumbens did not affect any (peri-)oral behavior, except for a small, but significant, increase in sniffing frequency (Fig. 4). Although it cannot be excluded that higher doses of DPI administered in the core might have been effective, the present data provide evidence that the shell and core are differentially susceptible to DPI with respect to oral behavior. It has to be noted that injections given into the core were centered in the region that was recently delineated as the so-called rostral pole of the nucleus accumbens (Zahm and Brog, 1992). The question of whether administration of DPI into more caudal parts of the dorsolateral nucleus accumbens is also ineffective in freely mov- ing rats remains to be investigated. However, it is already known that DPI given to anesthetized and spinalized rats enhances jaw movements only when administered into the shell, but not the caudal dorsolateral nucleus accumbens (Cools et al., 1993), namely, the core according to the nomenclature of Zahm and Brog (1992). These behavioral data together with the anatomical, pharmacological, and electrophysiological differences between the core and the shell as mentioned in the introductory remarks reveal that the nucleus accumbens is indeed a heterogeneous structure in all aspects.

Until now, studies on OFD in rats have mainly reported differences in frequency or duration of normal behaviors. In this study, a behavior was observed with abnormal morphology, 
namely, large-amplitude chewing. The observation that a small number of animals with control injections into the shell also showed this behavior (Fig. 5) is considered to be the result of aspecific stimulation of the shell, since it never occurred in untreated rats. Since DPI-administration into a striatal subarea of cats is also known to elicit abnormal, dyskinetic oral movements (Cools et al., 1976; Spooren et al., 1991), it appears justificd to conclude that DPI is a valid tool to study OFD in cats and rats.

Because the percentage of shell hits was rather low, dose dependency and antagonism of the effects of DPI were studied in the "shore" (the border region of the core and shell). DPI (5.0$10.0 \mu \mathrm{g}$ ) administered into the shore increased dose dependently oral behaviors. As shown in Figures 6 and 7, the dose-effect curve varied per distinct oral behavior. The finding that a maximum increase in tremor required a smaller dose of the dopamine $\mathrm{DA}_{\mathrm{i}}$ receptor agonist $\mathrm{DPI}$ than did a maximum increase in chewing suggests that tremor was more susceptible to changes in the dopaminergic activity than chewing. Indeed, systemic administration of the dopamine $D_{1}$ receptor agonist SKF 38393 increased tremor at lower doses than those producing an increase in chewing (Collins et al., 1990).

The dopamine $\mathrm{DA}_{i}$ receptor antagonist ergometrine attenuated the effect of DPI on chewing, tremor, and the frequency of sniffing. The effects of ergometrine on large-amplitude chewing and gnawing could not be assessed, since the dose of DPI used $(5 \mu \mathrm{g})$ did not significantly increase these behaviors. Taken together, the effects of DPI on oral behavior seemed to be mediated via the dopamine $\mathrm{DA}_{i}$ receptor, since the effects were dose dependent and could be attenuated with the dopamine $\mathrm{DA}_{1}$ antagonist ergometrine (cf. Cools et al., 1976; Woodman et al., 1981; Ploeger et al., 1991).

Since the shore encompasses the shell and the core and since only the shell is involved in oral behavior (see above), it appears justified to ascribe the shore effects to stimulation of dopamine $\mathrm{DA}_{\mathrm{t}}$ receptors located in the shell. Still, the effects of DPI administered into the shore were not fully identical to those elicited by DPI administration into the shell (compare Figs. 4, 6). One explanation might be that the shore region out of the shell is not completely devoid of DPI-sensitive receptors: additional stimulation of these receptors might have altered the effects elicited by stimulation of these receptors within the shell. An alternative explanation might be that the shell itself is not homogeneous, for the injections into the shore certainly reached different parts of the shell than did the injections into the shell (Fig. 2).

It has been postulated that hyperactive dopamine $\mathrm{DA}_{i}$ receptors belonging to the dopaminergic A8 and A10 neurons play an important role in the pathophysiology of OFD (Cools, 1980, 1983; Spooren et al., 1991). This postulate is based on studies with cats showing that stimulation of mesostriatal, dopamine $\mathrm{DA}_{\mathrm{i}}$ receptors elicits OFD. The present rodent study shows that dopamine $\mathrm{DA}_{\mathrm{i}}$ receptors in the shell, namely, an area innervated by dopaminergic A8 and A10 neurons (Gerfen et al., 1987; Deutch et al., 1988), are also involved in the display of abnormal oral behaviors, providing additional evidence in favor of the postulate mentioned above. In view of these findings, it is tempting to speculate that DPI administered into the shell of rats is an animal model for OFD in human. In this context it is relevant to note that both the shell itself as well as structures such as the dopaminergic A 10 cell group and the basolateral amygdala, which innervate the shell, are sensitive to stressors (see above; Sarter

\section{LARGE AMPLITUDE CHEW}

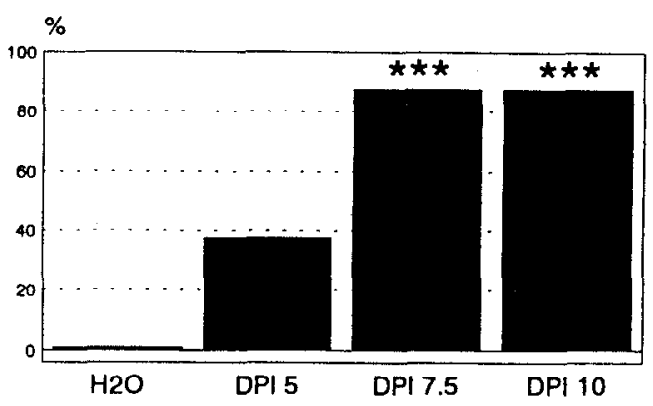

Figure 7. The effect of DPI $(5.0-10.0 \mu \mathrm{g})$ in the shore on the percentage occurrence of large-amplitude chewing during the experimental session. ***, $P<0.001$ compared with the $\mathrm{H}_{2} \mathrm{O}$ group.

and Markowitsch, 1985; Imperato et al., 1991; Deutch and Cameron, 1992), because OFD in human is known to be worsened by stress (Klawans et al., 1980). Future studies are required to test the validity of this animal model of OFD (cf. Waddington, 1990).

In conclusion, DPI in the shell of the nucleus accumbens increases the incidence of different oral behaviors and induces abnormal oral behavior, namely, large-amplitude chewing, via stimulation of dopamine $\mathrm{DA}_{\mathrm{i}}$ receptors.

\section{References}

Bardo MT, Hammer RP Jr (1991) Autoradiographic localization of dopamine D1 and D2 receptors in rat nucleus accumbens: resistance to differential rearing conditions. Neuroscience 45:281-290.

Berendse HW, Groenewegen HJ, Lohman AHM (1992) Compartmental distribution of ventral striatal neurons projecting to the mesencephalon in the rat. J Neurosci 12:2079-2103.

Bordi F, Carr D, Meller E (1989) Stereotypies elicited by injection of $N$-propylnorapomorphine into striatal subregions and nucleus accumbens. Brain Res 489:205-215.

Collins P, Broekkamp CLE, Jenner P, Marsden CD (1990) Purposeless chewing and facial tremor in rats: an electromyographical investigation. Br J Pharmacol 99:77.

Cools AR (1978) Ergometrine and its biphasic action at dopaminergic receptors in the nucleus accumbens. Pharmacology 16:93-98.

Cools AR (1980) Rapid development of hypersensitivity and hyposensitivity to apomorphine and haloperidol: role of norcpincphrinc receptor mechanisms in CNS. In: Advances in biochemical psychopharmacology, Vol 24, Longterm effects of neuroleptics (Cattabeni VF, Racagni G, Spano PF, Costa E, eds), pp 215-222. New York: Raven.

Cools AR (1983) Mesolimbic system and tardive dyskinesia: new perspectives for therapy. Mod Probl Pharmacopsychiatry 21:111123.

Cools AR (1986) Mesolimbic dopamine and its control of locomotor activity in rats: differences in pharmacology and light/dark periodicity between the olfactory tubercle and the nucleus accumbens. Psychopharmacology 88:451-459.

Cools AR (1990) Role of neostriatal and mesostriatal or mesolimbic dopaminergic fibres in Parkinson's disease with and without dementia: prospects, conccpts and facts. Jpn J Psychopharmacol 10:15-34.

Cools AR, Struyker Boudier HAJ, Van Rossum JM (1976) Dopamine receptors: selective agonists and antagonists of functionally distinct types within the feline brain. Eur J Pharmacol 37:283-293.

Cools AR, Kikuchi de Beltran K, Prinssen E, Koshikawa N (1993) Differential role of core and shell of the nucleus accumbens in jaw movements of rats. Neurosci Res Commun 13:55-61.

Deutch AY, Cameron DS (1992) Pharmacological characterization of dopamine systems in the nucleus accumbens core and shell. Neuroscience 46:49-56.

Deutch AY, Goldstein M, Baldino F Jr, Roth RH (1988) Telencephalic 
projections of the A8 dopamine cell group. Ann NY Acad Sci 537: $27-50$.

Gerfen CR, Herkenham M, Thibault J (1987) The neostriatal mosaic: 2. Patch- and matrix-directed mesostriatal dopaminergic and nondopaminergic systems. J Neurosci 7:3915-3934.

Heimer L, Zahm DS, Churchill L, Kalivas PW, Wohltman C (1991) Specificity in the projection patterns of accumbal core and shell in the rat. Neuroscience 41:89-125.

Imperato A, Puglisi-Allegra S, Casolini P, Angelucci I (1991) Changes in brain dopamine and acetylcholine release during and following stress are independent of the pituitary-adrenocortical axis. Brain Res 538:111-117.

Klawans HL, Goetz CG, Perlik S (1980) Tardive dyskinesia: review and update. Am J Psychiatry 137:900-908.

Koene P, Prinssen EPM, Cools AR (1993) Involvement of the nucleus accumbens in oral behavior in the freely moving rat. Eur J Pharmacol 233:151-156.

Koshikawa N, Koshikawa F, 'lomiyama K, Kikuchi de Beltran K, Kamimura F, Kobayashi M (1990) Effects of dopamine D1 and D2 agonists and antagonists injected into the nucleus accumbens and globus pallidus on jaw movements of rats. Eur J Pharmacol 182:375380.

Koshikawa N, Kikuchi de Beltran K, Saigusa T, Kobayashi M, Stephenson JD (1991) Cholecystokinin octapeptide and caerulein injection into the dorsomedial nucleus accumbens potentiate apomorphine-induced jaw movements in rats. Eur J Pharmacol 209:75-80.

Paxinos G, Watson C (1986) The rat brain in stereotaxic coordinates. North Ryde, Australia: Academic.

Pennartz CMA, Dolleman-Van der Weel MJ, Kitai ST, Lopes da Silva FH (1992) Presynaptic dopamine D1 receptors attenuate excitatory and inhibitory limbic inputs to the shell region of the rat nucleus accumbens studied in vitro. J Neurophysiol 67:1325-1334.

Pijnenburg AJJ, Honig WMM, Van Rossum JM (1976) Effects of chemical stimulation of the mesolimbic dopamine system upon locomotor activity. Eur J Pharmacol 35:45-58.
Ploeger GE, Willemen APM, Cools AR (1991) Role of the nucleus accumbens in social memory in rats. Brain Res Bull 26:23-27.

Prinssen EPM, Koene P, Heeren DJ, Cools AR (1992) Jaw muscle activity, the nucleus accumbens and dopaminergic agonists: a new approach. Brain Res Bull 28:775-780.

Sarter M, Markowitsch HJ (1985) Involvement of the amygdala in learning and memory: a critical review with emphasis on anatomical relations. Behav Neurosci 99:342-380.

Spooren WPJM, Groenewegen HJ Cools AR (1991) Subregions of the caudate nucleus and their in- and output channels in oro-facial dyskinesia: a behavioral and retrograde tracing study in the cat. Brain Res 539:85-93.

Struyker Boudier HAJ, Teppema L, Cools AR, Van Rossum JM (1975) (3,4-dihydroxyphenylamino)-2-imidazoline (DPI): a new, potent stimulant at dopamine receptors mediating neuronal inhibition. J Pharm Pharmacol 27:882-883.

Voorn P, Gerfen CR, Groenewegen HJ (1989) Compartmental organization of the ventral striatum of the rat: immunohistochemical distribution of enkephalin, substance $P$, dopamine and calcium-binding protein. J Comp Neurol 289:189-201.

Waddington JL (1990) Spontaneous orofacial movements induced in rodents by very long-term neuroleptic drug administration: phenomenology, pathophysiology and putative relationship to tardive dyskinesia. Psychopharmacology 101:431-447.

Woodman OL, Medgett IC, Lang WJ, Rand MJ (1981) Agonistic actions of DPI (2-(3,4-dihydroxyphenylimino)-imidazoline) on $\alpha$-adrenoceptors and dopamine receptors. Eur J Pharmacol 75:11-19.

Zaborsky L, Alheid GF, Beinfeld MC, Eidens LE, Heimer L, Palkovits M (1985) Cholecystukinin innervation of the ventral striatum: a morphological and radioimmunological study. Neuroscience 14:427453.

Zahm DS, Brog JS (1992) On the significance of subterritories in the "accumbens" part of the rat ventral striatum. Neuroscience 50:751767. 